\title{
Role of iris changes as a cause of blindness in lepromatous leprosy
}

\author{
T. J. FFYTCHE \\ From St Thomas's Hospital, Lambeth Palace Road, London SE1 7EH
}

SUMmaRY Clinical and pathological investigations in a group of 113 patients with leprosy of long duration demonstrated the importance of iris changes as a cause of blindness. In lepromatous leprosy the so called 'chronic iritis' produces iris atrophy with small nonreacting pupils which exaggerate the visual impairment created by developing lens changes and corneal opacities. The cause of this 'chronic iritis' is believed to be neuroparalytic from early involvement of the small nerves of the iris, particularly the autonomic supply. Clinical and pharmacological evidence for this theory is supported by the histological changes observed in 18 specimens of iris removed during the course of cataract surgery, with progressive atrophy of the iris preferentially affecting the dilator muscle and leading to a nonreacting miosed pupil. Further pharmacological and histological studies are to be undertaken on lepromatous patients with iris involvement with a view to establishing possible methods of prevention.

It has for long been realised that the main causes of blindness in leprosy lie in disease of the anterior segment and that the condition rarely affects the tissues at the posterior pole of the eye. Ocular damage in leprosy occurs in 4 ways: (1) facial and trigeminal nerve involvement; (2) hypersensitivity reactions; (3) direct bacterial invasion; (4) secondary infection.

FACIAL AND TRIGEMINAL INVOLVEMENT Leprosy is essentially a neural disease with infection and eventual destruction of superficial nerves by Mycobacteria leprae. The anatomical position of the facial nerve, especially the zygomatic branch, and the superficial branches of the trigeminal nerve make these structures vulnerable to infection in all forms of leprosy, giving rise to abnormalities of lid position and abolition of the normal blink and corneal reflexes. A combination of these 2 nerve palsies may occur early in the course of the disease and lead to exposure keratitis, with its consequent corneal damage and opacification. The incidence of these major corneal problems is, however, less than might be expected, since preservation of the normal Bell's phenomenon prolongs the protection of the cornea. ${ }^{12}$ Even so, facial palsy has been considered to be the second commonest cause of blindness in leprosy. ${ }^{3}$

Correspondence to T. J. ffytche.
HYPERSENSITIVITY REACTIONS

In all forms of leprosy, but particularly when a change in polarity occurs, a hypersensitivity reaction can take place. This 'lepra' reaction usually arises when therapy is being commenced or withdrawn, but can also develop spontaneously..$^{4-6}$ The reaction is generalised, with acute swelling of skin lesions, tender nerves, and at times severe fever, and these signs have given rise to the alternative name of erythema nodosa leprosum. There is often an associated acute iritis and at times a nephritis. ${ }^{7}$ The clinical manifestations are believed now to be caused by circulating immune complexes becoming deposited in the affected tissues ${ }^{6} 8$ rather than a response to bacteria, for although $M$. leprae have been found in the anterior chamber by paracentesis $^{9-12}$ it is not known what role they play in the pathogenesis of the acute uveitis, and the lepra reaction can occur in the absence of organisms. ${ }^{8}$

The eye develops an acute iritis which is usually bilateral and does not differ in its clinical manifestations from other forms of acute nonleprous iritis. The disease has a sudden painful onset, and, if untreated, the eye can be permanently damaged within 24-72 hours. ${ }^{13}$ Aqueous flare and cells, keratic precipitates, hypopyon, and synechiae with seclusio pupillae and secondary glaucoma can occur with secondary cataract and eventual phthisis. 
DIRECT BACTERIAL INVASION

Direct bacterial invasion occurs only in lepromatous leprosy. It is now considered by most authors to take place as a result of a bacteraemia following infection, ${ }^{781214-16}$ although some spread may occur from infected lacrimal and nasal passages, ${ }^{6} 717$ but this method of spread may be rare. ${ }^{13}$

The invasion of the cornea by leprosy bacilli gives rise to a true leprous keratitis affecting corneal nerves and later the superficial stroma. This condition of superficial stromal keratitis is regarded as pathognomonic for lepromatous leprosy. ${ }^{18}$ It has been alternatively called 'superficial avascular keratitis', ${ }^{19}$ 'avascular subepithelial punctate keratitis', 20 'diffuse punctate lepromatous keratitis', ${ }^{21}$ and 'diffuse superficial punctate keratitis'." The condition is, however, rarely serious for vision unless corneal deposits are substantial and is often asymptomatic. $^{1921}$ It may progress to form a circumferential pannus or an interstitial keratitis which does not produce the same degree of vascularisation as syphilis ${ }^{219}$ and which rarely causes severe visual loss. ${ }^{22} \mathrm{~A}$ sclerosing form of keratitis may follow as a late change. ${ }^{13}$

Occasionally a leproma may occur in the centre of the cornea with substantial visual loss. This rare lesion is known in some parts of the world as Ruato's corneal leproma. It seems to be regional, occurring in South America ${ }^{23}$ and Japan, ${ }^{18}$ and it may be provoked by local climatic conditions. The corneal leproma is responsible for only a very small proportion of blindness in leprosy.

Other forms of corneal disease and opacification occur as a result of exposure and neuroparalytic keratopathy and include band-shaped degeneration and various chronic degenerative conditions. Direct invasion of the episclera occurs as an early event in lepromatous leprosy and gives rise to small nodules at the limbus. ${ }^{47}$ They are often a prelude to leprous keratitis, and occasionally they may grow across the corneal margin as large lepromatous nodules, which interfere with vision. ${ }^{21}$

\section{Iris}

Direct bacterial invasion of the iris and ciliary body produces the so-called 'chronic iritis,' which is considered by many to be the commonest cause of visual impairment in leprosy $152024-28$ and termed by Weekeroon as the "cause par excellence of blindness.' The condition which is also known as 'insidious anterior uveitis' ${ }^{\prime 29}$ and 'chronic plastic iritis'2030 commences quietly several years after infection. It is characterised by a lack of symptoms and overt signs, though slit-lamp examination may show aqueous flare and cells with fine keratic precipitates scattered all over the corneal endo- thelium. ${ }^{31}$ Eventually iris atrophy develops, with loss of iris stroma and epithelium, miosis, and the formation of holes in the stroma resembling at times the appearance in essential iris atrophy. Synechiae may be present and were originally noted by Hansen and Bull ${ }^{32}$ when they described 'iritis without violent symptoms with exudation around the borders of the pupils and adhesions of the lens in patients who have not complained of pain or derangement of sight.' This tendency to form synechiae is not, however, common to all cases with chronic iritis. ${ }^{33} 34$ Pupil reactions have been noted to be sluggish and resistant to conventional mydriatics early in the disease, ${ }^{2420233335}$ and a premature presbyopia, even in apparently normal patients with lepromatous leprosy, was noted by Wood. ${ }^{24}$ Equally asymptomatic is the development of 'iris pearls' in the early stages of the disease. These small glistening white lesions are pathognomonic for lepromatous leprosy and have been shown histologically to be composed of collections of tightly packed living and dead bacilli lying within mononuclear cells (also called 'foam' or 'lepra' cells), with little accompanying inflammation or foreign body reaction. ${ }^{336}$ Iris pearls usually develop within a year or two of the commencement of the iritis and occur mainly at the pupil margin around the collarette, described as resembling a necklace ${ }^{33}$ or the beads of a rosary..$^{37}$

Pearls may develop deep in the iris stroma and occasionally at the periphery. Their natural history is one of slow increase in size and aggregation. They may become pedunculated and eventually drop off into the anterior chamber, where they are well tolerated and produce no inflammatory reaction. They are a transient phenomenon and are rarely responsible for any visual impairment.

Bacterial invasion of the iris may also give rise to the formation of a nodular leproma-sometimes called 'voluminous leproma of the iris' ${ }^{25}$ These are rare single polymorphic masses which may occasionally sufficiently disrupt the iris architecture to interfere with vision.

\section{Lens}

Direct invasion of the lens by bacilli has never been demonstrated and many authors consider that there is no true leprosy cataract and that the lens changes are those seen in a normal aging population. ${ }^{4} 7253839$ A secondary cataract may certainly develop after the acute iritis associated with hypersensitivity, but some authors acknowledge a higher incidence of secondary cataract following chronic iritis. ${ }^{21420} \mathrm{~A}$ possible cause for cataract in lepromatous leprosy was suggested by Prabhakaran, ${ }^{40}$ who noted that the leprosy bacilli reacted with dopa, which is normally 
found in the iris and ciliary body, and that this reaction is produced with high local concentrations of quinones, which are known to be cataractogenic.

\section{SECONDARY INFECTION}

Loss of corneal sensitivity, poor nutritional control, and exposure and diminished tear production all combine to make the cornea susceptible to secondary bacterial, viral, and fungal infections. The additional destruction of the nose and nasolacrimal passages in advanced cases increases the local reservoir of pathogenic organisms.

The conclusions from a survey of the world literature and from personal experience are that chronic iritis is responsible for the major part of blindness in lepromatous leprosy, although the role of lens changes is still uncertain. A study of lepromatous patients with advanced ocular disease requiring surgery was undertaken with a view to determining the underlying pathogenesis of this chronic iritis in order that further preventive measures might be examined.

\section{Material and methods}

A total of 113 patients with advanced eye disease related to leprosy were examined during 2 visits to the Wilson Leprosy Centre and Rehabilitation Hospital at Yosu, South Korea, and a general analysis of this group of patients is presented in a separate publication. ${ }^{34} 110$ patients had the lepromatous form of the disease, 2 had the tuberculoid form, and 1 was classed as borderline. Slit-lamp examination was carried out in all cases, and the iris changes observed in 198 nonphthisical eyes are tabulated in Table 1.

Cataract surgery was undertaken in 88 patients, and histological and immunological examinations were carried out in 18 specimens of iris removed by broad iridectomy. Fifteen of these patients had lepromatous leprosy, 2 had the tuberculoid form,

Table 1 Iris changes in nonphthisical eyes

\begin{tabular}{lrc}
\hline Normal iris & 32 & $16 \%$ \\
Previous iridectomy & 19 & $9 \cdot 5 \%$ \\
Iris atrophy & 113 & $57 \%$ \\
Posterior synechiae & 66 & $33 \%$ \\
Combined atrophy & & \\
$\quad$ and synechiae & 49 & $25 \%$ \\
Seclusio pupillae & 7 & $3 \cdot 5 \%$ \\
Iris floccules & 3 & $1 \cdot 5 \%$ \\
Iris pearls & 4 & $2 \%$ \\
Keratic precipitates & 6 & $3 \%$ \\
Active iritis & 3 & $1 \cdot 5 \%$ \\
Iris naevus & 2 & $1 \%$ \\
\hline
\end{tabular}

and 1 was classed as borderline. In all patients the leprosy had been inactive for at least 3 years and in most cases for 10 years or more.

\section{Case reports}

CASE 9

A 60-year-old female with lepromatous leprosy for 22 years. Negative for at least 12 years.

Right eye. Hand movements. Corneal scarring, posterior synechiae, cataract. Left eye. Hand movements. Posterior synechiae, cataract. Left intracapsular lens extraction, postoperative visual acuity $6 / 24$.

Histology. Iris showed diffuse infiltration with plasma cells and lymphocytes with occasional macrophages Dilator fibres present sphincter distorted by trauma and inflammation

Immunopathology. IgG $169 \mathrm{IU} / \mathrm{ml}$, IgA $193 \mathrm{IU} / \mathrm{ml}$, IgM $93 \mathrm{IU} / \mathrm{ml}$ Anti-smooth-muscle antibody titre $1: 10$.

\section{CASE 16}

A 73-year-old female with lepromatous leprosy for 25 years. Negative for at least 12 years.

Right eye. No perception of light (NPL). Extensive corneal scarring with no view of intraocular structures. Left eye. Counting fingers. Band shaped keratopathy, iris atrophy and cataract. Right enucleation carried out and left intracapsular lens extraction. Postoperative visual acuity 6/60.

Histology. Marked lymphocyte and plasma cell infiltration of the perilimbal bulbar conjunctiva with some plasmacytoid cells; Russell bodies also present. Stromal vascularisation and cellular infiltration of the cornea with a little superficial pannus towards the periphery with destruction of the underlying Bowman's layer. Scattered groups of leucocytes adherent to Descemet's membrane, and the iris and ciliary body were the site of a diffuse lymphoid infiltration with some Russell bodies present. The sphincter pupillae was clearly recognisable but only an occasional dilator fibre could be identified (Fig. 1). The lens, choroid, and retina were normal. Specific staining for leprosy bacilli was negative.

CASE 102

A 77-year-old male with lepromatous leprosy for 52 years. Negative for at least 15 years.

Right eye. Light perception. Corneal scarring, iris atrophy and posterior synechiae, cataract. Left eye. NPL. Phthisis. Right extracapsular lens extraction. Postoperative visual acuity $3 / 60$.

Histology. Iris showed diffuse infiltration of the stroma with lymphocytes and plasma cells. Sphincter muscle present but dilator fibres were equivocal. 
Fig. 1 Case 160. Histological section of iris showing easily identified sphincter muscle but only occasional dilator fibres.

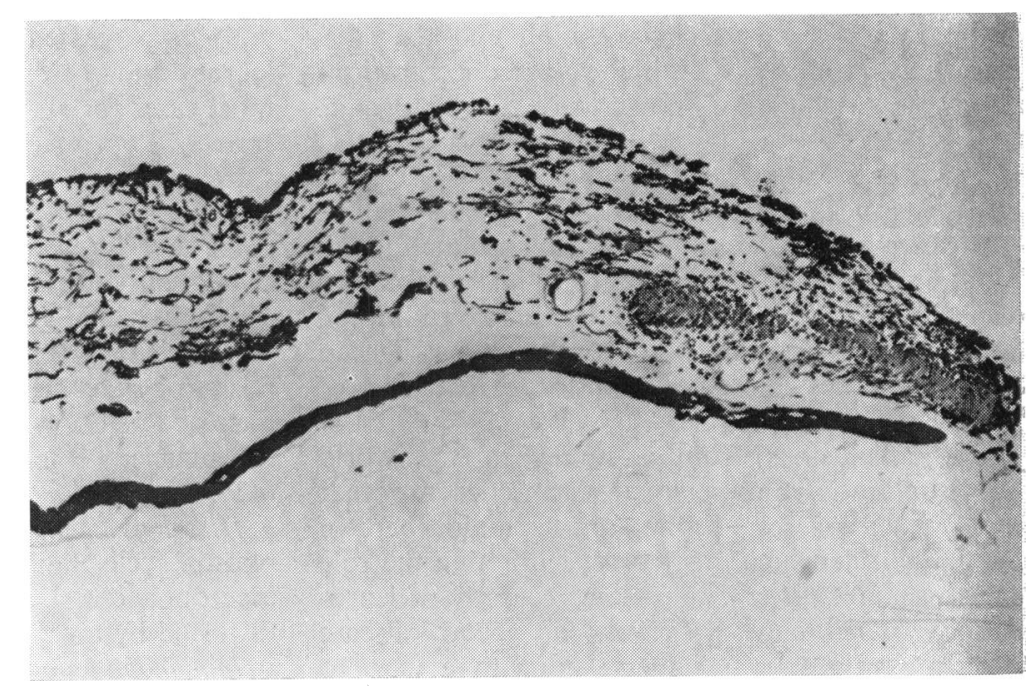

Immunopathology. IgG $272 \mathrm{IU} / \mathrm{ml}, \operatorname{IgA} 277 \mathrm{IU} / \mathrm{ml}$, IgM $270 \mathrm{IU} / \mathrm{ml}$. Antismooth-muscle antibody titre $1: 10$ antigastric antibody titre $1: 4$.

CASE 103

A 58-year-old male with lepromatous leprosy for 40 years. Negative for at least 15 years.

Right eye. Counting fingers. Corneal opacities, iris atrophy, cataract (Fig. 2). Left eye. 3/60. Corneal opacities, iris atrophy, cataract. Right intracapsular lens extraction; postoperative visual acuity 6/60.

Histology: Iris showed patchy infiltration with lymphocytes and plasma cells. Sphincter seemed to be intact but no dilator fibres seen.

Immunopathology. Antinuclear antibody titre 1:10.

CASE 208

A 65-year-old male with tuberculoid leprosy for 28 years. Negative for at least 12 years.

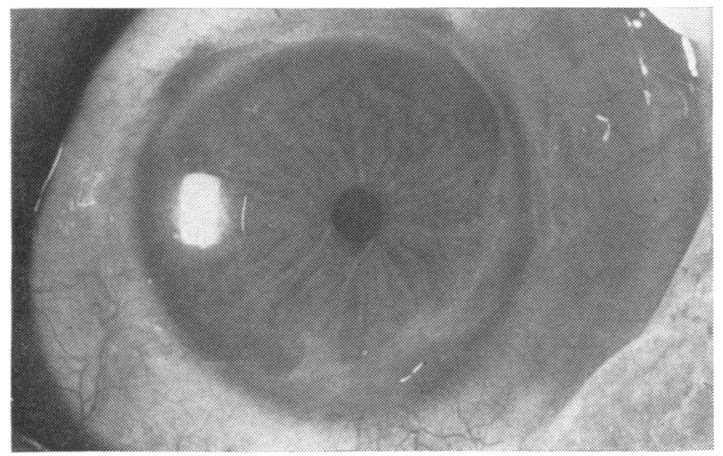

Fig. 2 Case 103. Small nonreacting pupil with iris atrophy and intact sphincter. Vision, counting fingers.
Right eye. 6/36. Trichiasis, cataract. Left eye. Counting fingers. Trichiasis, cataract. Left intracapsular lens extraction, postoperative visual acuity 6/9.

Histology. Iris was essentially normal with dilator and sphincter muscle discernible.

Immunopathology. $1 \mathrm{gG} 311 \mathrm{IU} / \mathrm{ml}$, IgA $332 \mathrm{IU} / \mathrm{ml}$, IgM $130 \mathrm{IU} / \mathrm{ml}$ Antismooth-muscle antibody titre $1: 40$.

\section{CASE 209}

A 66-year-old male with lepromatous leprosy for 46 years. Negative for at least 12 years.

Right eye. Counting fingers. Iris atrophy and posterior synechiae, cataract. Left eye: NPL. Phthisis. Right intracapsular lens extraction; postoperative visual acuity $6 / 12$.

Histology. Iris showed generalised atrophy without signs of any active inflammation. Loss of dilator muscle was noted but the state of the sphincter could not be assessed.

Immunopathology. IgG $217 \mathrm{IU} / \mathrm{ml}$, IgA $165 \mathrm{IU} / \mathrm{ml}$, IgM $157 \mathrm{IU} / \mathrm{ml}$.

\section{CASE 261}

A 71-year-old male with lepromatous leprosy for 63 years. Negative for at least 18 years.

Right eye. Counting fingers. Lagophthalmos, iris atrophy, cataract. Left eye. 6/36. Iridectomy, aphakia, normal fundus. Right intracapsular lens extraction. Postoperative visual acuity $6 / 24$.

Histology. Iris showed diffuse infiltration with moderate numbers of lymphocytes and plasma cells. Almost complete absence of dilator muscle was noted.

Immunopathology. Aqueous showed the presence of $\operatorname{lgG}$ but no IgA or IgM. 
CASE 377

A 56-year-old male with lepromatous leprosy for 25 years. Negative for at least 10 years.

Right eye. Counting fingers. Band-shaped keratopathy, enlarged corneal nerves. Iris atrophy, cataract. Left eye. Light perception. Early band shaped keratopathy. Iris naevus, iris atrophy, cataract. Left intracapsular lens extraction; postoperative visual acuity 6/36.

Histology. Iris showed diffuse infiltration with lymphocytes and plasma cells. There was almost complete absence of the dilator and sphincter muscles. The iris naevus showed no unusual features.

\section{CASE 384}

A 63-year-old male with lepromatous leprosy for 42 years. Negative for at least 10 years.

Right eye. Counting fingers. Corneal opacities, iris atrophy and posterior synechiae, cataract. Left eye. $3 / 60$. Iris atrophy, cataract. Right extracapsular lens extraction. Postoperative visual acuity $6 / 36$.

Histology. Iris showed mild degree of infiltration with plasma cells and lymphocytes. Dilator muscle fibres present in normal amounts.

Immunopathology. IgG $202 \mathrm{IU} / \mathrm{ml}$, IgA $183 \mathrm{IU} / \mathrm{ml}$, IgM 302 IU $/ \mathrm{ml}$.

\section{CASE 802}

A 56-year-old male with lepromatous leprosy for 39 years. Negative for 12 years.

Right eye. Counting fingers. Lagophthalmos, corneal opacities, iris atrophy, cataract. Left eye. $3 / 60$. Lagophthalmos, band-shaped keratopathy, iris atrophy, cataract. Right intracapsular lens extraction. Postoperative visual acuity $3 / 60$.

Histology. Iris showed some atrophy with a few chronic inflammatory cells. Dilator fibres appeared to be normal; sphincter not available for study.

Immunopathology. IgG $189 \mathrm{IU} / \mathrm{ml}$, IgA $158 \mathrm{IU} / \mathrm{ml}$, IgM $118 \mathrm{IU} / \mathrm{ml}$.

\section{CASE 1019}

A 60-year-old female with borderline leprosy for 37 years. Negative for 12 years.

Right eye. 3/60. Vascularised corneal scar, iris atrophy, and posterior synechiae, cataract. Left eye. NPL. Advanced vascularised corneal scarring. Right extracapsular lens extraction; postoperative visual acuity $6 / 36$.

Histology. Iris showed infiltration with small number of plasma cells and lymphocytes, some plasmacytoid cells seen also. Dilator muscle present.

Immunopathology. Aqueous showed IgG but no $\operatorname{IgA}$ or IgM.
CASE 1144

A 63-year-old female with lepromatous leprosy for 54 years. Negative for 12 years.

Right eye. Hand movements. Iris atrophy and posterior synechiae, cataract. Left eye. Hand movements. Iris atrophy and posterior synechiae with dislocated lens. Right intracapsular lens extraction; postoperative visual acuity $6 / 24$.

Histology. Iris showed mild infiltration with lymphocytes and plasma cells. The sphincter appeared to be intact but hardly any dilator fibres could be identified.

Immunopathology. IgG $237 \mathrm{IU} / \mathrm{ml}$ IgA $214 \mathrm{IU} / \mathrm{ml}$, IgM $228 \mathrm{IU} / \mathrm{ml}$. Rheumatoid factor positive to $1: 10$ dilution, antismooth-muscle antibody titre $1: 40$.

\section{CASE 1415}

A 49-year-old male with tuberculoid leprosy for 31 years. Negative for 12 years.

Right eye. 3/60. Posterior synechiae and cataract. Left eye. 3/60. Posterior synechiae and cataract. Right intracapsular lens extraction; postoperative visual acuity $6 / 24$.

Histology. Iris showed heavy but patchy infiltration with lymphocytes and plasma cells and some macrophages with a distinct granulomatous arrangement in a few areas. Sphincter and dilator muscle were present.

Immunopathology. IgG $243 \mathrm{IU} / \mathrm{ml}, \mathrm{IgA} 74 \mathrm{IU} / \mathrm{ml}$, IgM $163 \mathrm{IU} / \mathrm{ml}$. Rheumatiod factor positive to $1: 10$ dilution. Aqueous showed IgG but no IgA or IgM.

\section{CASE 2165}

A 75-year-old male with lepromatous leprosy for 54 years. Negative for 12 years.

Right eye. Counting fingers. Lagophthalmos, trichiasis, band-shaped keratopathy, iris atrophy, cataract. Left eye. NPL. Lagophthalmos, corneal scarring, cataract, early phthisis. Right extracapsular lens extraction; postoperative visual acuity $3 / 60$.

Histology. Iris showed no sign of active inflammation. Dilator muscle was identified.

Immunopathology. IgG $320 \mathrm{IU} / \mathrm{ml}$, IgA $350 \mathrm{IU} / \mathrm{ml}$, IgM $395 \mathrm{IU} / \mathrm{ml}$. Rheumatoid factor positive for $1: 10$ dilution.

CASE 2219

A 51-year-old male with lepromatous leprosy for 40 years. Negative for 12 years.

Right eye. NPL. Gross corneal scarring, early phthisis.

Left eye. Counting fingers. Corneal opacities, iris atrophy, cataract. Left intracapsular lens extraction; postoperative visual acuity 6/24.

Histology. Iris showed scattered foci of lympho- 


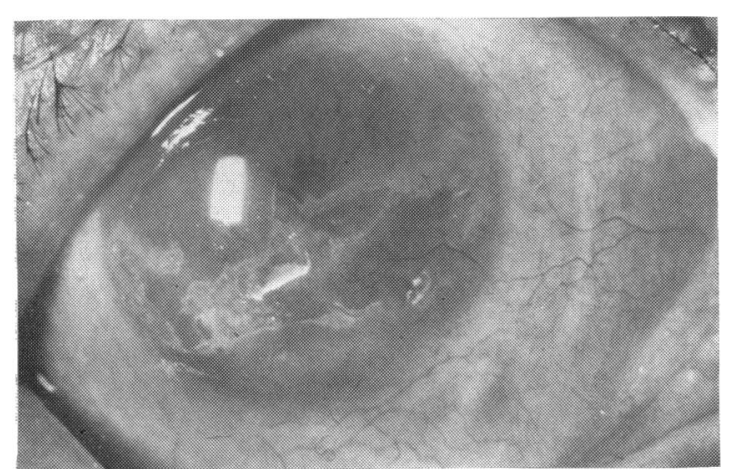

Fig. 3 Case 2294. Vascularised corneal scar with advanced iris atrophy and nonreacting pupil. The ragged outline of the pupil margin associated with loss of iris stroma is visible above the corneal scar. Vision, counting fingers.

cytes and plasma cells. Sphincter intact but there was a complete absence of the dilator muscle.

Immunopathology. IgG $197 \mathrm{IU} / \mathrm{ml}$, IgA $258 \mathrm{IU} / \mathrm{ml}$, IgM $67 \mathrm{IU} / \mathrm{ml}$. Antismooth-muscle antibody titre $1: 10$.

\section{CASE 2294}

A 62-year-old male with lepromatous leprosy for 41 years. Negative for at least 5 years.

Right eye. Counting fingers. Vascularised corneal scar. Iris atrophy with posterior synechiae. (Fig. 3). Left eye. NPL. Vascularised corneal scar, cataract. Right extracapsular lens extraction; postoperative visual acuity $3 / 60$ with capsule remnants.

Histology. Iris showed heavy infiltration with plasma cells and lymphocytes and a few Russell bodies. No muscle tissue identified.

Immunopathology. IgG $365 \mathrm{IU} / \mathrm{ml}$, IgA $420 \mathrm{IU} / \mathrm{ml}$, IgM $410 \mathrm{IU} / \mathrm{ml}$. Rheumatoid factor positive in dilution of $1: 10$, antismooth muscle-antibody titre $1: 10$.

\section{CASE 2678}

A 70-year-old female with lepromatous leprosy for 33 years. Negative for at least 11 years.

Right eye. Counting fingers. Iris atrophy and posterior synechiae, cataract. Left eye. NPL. Phthisis. Right intracapsular lens extraction; postoperative visual acuity $6 / 60$.

Histology. Iris showed moderate infiltration with plasma cells, lymphocytes, and scanty macrophages. Sphincter muscle prominent but dilator muscle appeared to have atrophied.

CASE 3768

A 70-year-old male with lepromatous leprosy for 32 years. Negative for at least 3 years.

Right eye. Counting fingers. Band-shaped de- generation, iris atrophy and posterior synechiae, cataract. Left eye. NPL. Old corneal abscess. Right intracapsular lens extraction; postoperative visual acuity $6 / 60$.

Histology. Iris showed a small amount of patchy leucocytic infiltration. Dilator muscle showed atrophy; sphincter not available for examination.

Immunopathology. IgG $206 \mathrm{IU} / \mathrm{ml}$, IgA $244 \mathrm{IU} / \mathrm{ml}$, IgM $135 \mathrm{IU} / \mathrm{ml}$.

\section{Results}

All 18 specimens of iris showed negative immunoperoxidase labelling for antibodies, and no acid-fast bacilli were observed with a modified Ziehl-Neelsen stain. Additional measurements of serum angiotensin converting enzymes (SACE) were carried out in a total of 38 patients with active and inactive disease-27 lepromatous of whom 16 had active disease, 7 borderline of whom 4 were active, and 4 tuberculoid of whom 2 were active. The serum was analysed at the Royal Northern Hospital and all examinations were found to be negative. ${ }^{41}$

The results of the IgG, IgA, and IgM measurements and other immunological studies in the serum and aqueous were disappointing. In 4 out of 12 cases the serum IgG, IgA, and IgM levels were raised, and 1 patient had elevated antismoothmuscle antibody titres. Antigastric, antinuclear, and rheumatoid factors were all normal. Aqueous studies in 4 cases showed IgG present in 3 , but $\operatorname{IgA}$ and IgM absent in all specimens. The results in this small sample did not suggest any active granulomatous process but reflected chronic low-grade nonspecific inflammatory changes.

Morphological examination of the iris in the $\mathbf{1 5}$ patients with lepromatous leprosy showed that the dilator muscle was absent or grossly atrophied in 11 eyes $(73 \%)$, whereas the sphincter was atrophied in only 2 eyes. In 3 other specimens the sphincter was not seen, presumably because it had remained adherent to the lens at the time of operation, indicating the presence of posterior synechiae. Both the dilator and sphincter muscles appeared to be normal in the remaining 3 patients with tuberculoid and borderline leprosy. No relationship between the iris changes and the duration of the disease or the immunological abnormalities could be established.

Studies on the morphology and histology of the iris nerves were not carried out but will be the subject of future investigations.

\section{Discussion}

The clinical examinations carried out in this study and many others emphasise the importance of iris 
involvement as a cause of visual impairment in lepromatous leprosy, but the underlying pathological processes have not yet been fully determined. The manifestations and late effects of the acute iritis which occurs as part of the 'lepra' reaction are well recognised and are no different from the iritis seen in other granulomatous disease. Prompt treatment with local mydriatics and steroids must be instituted in order to avoid severe visual complications. By contrast the so-called 'chronic iritis' that affects such a large percentage of patients with lepromatous leprosy of long duration, especially those living in temperate climates, seems much more resistant to conventional steroid and mydriatic therapy and is typically characterised by a lack of symptoms and overt clinical signs in the early stages; its behaviour is unlike a chronic inflammatory condition.

Evidence from the literature and from personal observations suggest that this 'chronic iritis' of lepromatous leprosy is not a true inflammation but rather a form of neuroparalytic iritis caused by early involvement of the iris nerves, particularly the autonomic fibres. The leprosy bacillus is known to attack fine nerve fibres, preferentially those lying in the coolest parts of the body-the skin of the extremities, nose, ears, testis. Measurements of temperature gradients in rabbits show that there is a difference of $6^{\circ} \mathrm{C}$ between the temperature of the corneal surface and the orbit, with a steady gradient throughout the ocular tissues, with the iris about $3.5^{\circ} \mathrm{C}$ below body temperature. ${ }^{42}$ The iris contains sensory and autonomic nerves, the latter being small, nonmyelinated, containing Schwann cells, and, in the case of sympathetic nerves, being intimately related to the myoepithelial cells of the dilator muscle. ${ }^{43}$

Leprosy bacilli entering the eye as part of a generalised bacteraemia that is known to occur in the early stages of lepromatous leprosy are therefore likely to lodge in the nerve fibres of the cornea, iris, and ciliary body, where the temperature is lower than the general body temperature, and the smaller nonmyelinated autonomic nerves are more vulnerable than the larger myelinated sensory nerves. Involvement of corneal nerves is a well recognised clinical entity, with local beading and thickening followed by atrophy, ${ }^{17}{ }^{194-46}$ and pathological studies confirm leprous infiltration of the cytoplasm of the Schwann cells with the development of nodules and eventual destruction. ${ }^{19} \mathrm{~A}$ parallel situation exists clinically in the iris with the formation of iris pearls. These lesions are asymptomatic and do not appear to be associated with any marked inflammatory changes in the anterior chamber. They occur early in the course of lepromatous leprosy and they also eventually disappear, and their resemblance to corneal beading has previously been commented on. ${ }^{20}$ Iris pearls accumulate preferentially around the pupil margin, though they occur also in the deep iris stroma and occasionally at the periphery. This distribution conforms with the major network of iris nerves which form a plexus around the pupil. Histologically the iris pearls consist of tightly packed bacilli within mononuclear cells with little accompanying foreign body reaction or inflammatory changes-a pattern which is repeated in lepromas related to nerve tissue elsewhere in the body. The evidence that iris pearls represent lepromatous infiltration and later destruction of iris nerves is strong but not yet conclusive. Electron microscopic studies have shown lepra cells infiltrating the iris stroma and destroying nonmyelinated nerves, ${ }^{47}$ but the same study revealed that many of the larger nerves were unaffected, and it was therefore suggested that the iris involvement was primarily a myositis. Personal observation during cataract surgery in lepromatous patients also showed that in some patients, even with advanced iris atrophy, pulling on the iris caused some discomfort, indicating that some sensory fibres remained intact. A possible explanation is that the larger sensory nerves, which are myelinated, are more resistant to lepromatous infiltration and damage, but obviously further histological evidence for this must be sought.

The suggestion that the 'chronic iritis' of lepromatous leprosy is in reality a neuroparalytic iritis, however, receives considerable clinical support. The increasingly sluggish pupils and their poor response to mydriatics have already been commented on, together with the premature presbyopia in apparently normal patients. An important pharmacological study by Swift and Bauschard ${ }^{48}$ on lepromatous patients, some of whom had no overt signs of ocular involvement, showed that in 11 out of 20 patients the pupils dilated with $\mathrm{L}$-epinephrine, whereas dilatation occurred in only 1 out of 20 normal subjects. These responses indicated an early autonomic denervation hypersensitivity, and the comment was made that the leprous iris was a prime example of peripheral postganglionic denervation. Slem $^{5}$ also considered the iritis to be neurotrophic, comparing the appearance with essential iris atrophy and recommending further studies.

These observations and the results of the present study suggest early involvement of the autonomic nerves in the lepromatous iris, with their eventual destruction, and the late effects of neuroparalysis include the slow atrophy of the iris muscle and associated chronic low-grade inflammatory changes.

Histological studies presented demonstrate that in 11 out of 15 cases the dilator muscle was preferenti- 
ally affected in this atrophic process. The reason for this has not yet been established, but it may reflect the relative size of the muscle in comparison with the sphincter pupillae, the difference in the muscle fibre, and the intimate relationship of the dilator fibres with the terminal sympathetic nerves. This differential atrophy of the iris muscles associated with autonomic denervation produced the characteristic miosed nonreacting pupil, and this was augmented in a number of cases (24\% in this series) by posterior synechiae. Since dilator function is likely to be prejudiced in the early stages of the 'chronic iritis' of lepromatous leprosy, it is not surprising that the conventional anticholinergic mydriatics are ineffective.

It is possible that the clinical signs of this silent iritis with faint flare, a few cells, and white eyes without any discomfort are the manifestations of the slow breakdown of the iris muscle following autonomic denervation, and the absence of widespread inflammatory changes in many of the iris specimens examined histologically together with lack of any evidence of gross immunological abnormalities in the sera and aqueous lends support to this theory.

More research is required into the pharmacological responses and neuropathology of the iris in the early stages of lepromatous leprosy, since identification of autonomic involvement could lead to therapy designed to prevent dilator atrophy with its complication of persistent miosis. The clinical studies in lepromatous patients emphasise how often the small nonreacting pupil plays a major role in the cause of the visual impairment, and prevention of these changes would be a positive step in combating blindness in these already severely disabled patients.

None of this work would have been possible without the help and support of Professor A. Garner, of the Institute of Ophthalmology, who carried out the histological studies of the iris specimens. I thank Dr Stanley C. Topple, Dr Mia Topple, Dr Akiko Obara, Dr Yoo Kyeung Un, and all the staff of the Wilson Leprosy Centre and Rehabilitation Hospital, Yosu, South Korea for the invaluable help and hospitality.

I am indebted to LEPRA and St Thomas's Hospital for financial aid and to Mrs Lesley Gibbons for her secretarial assistance.

\section{References}

1 Emiru VP. Ocular leprosy in Uganda. Br J Ophthalmol 1970; 54: 740-3.

2 Shields JA, Waring GO, Monte LG. Ocular findings in leprosy. Am J Ophthalmol 1974; 77: 880-90.

3 Krassai A. Corneal sensitivity in lepromatous leprosy. Int J Lepr 1970; 38: 422-7.

4 Weekeroon L. Ocular leprosy in Ceylon. Br J Ophthalmol 1969; 53: 457-65.

5 Slem G. Clinical studies of ocular leprosy. Am J Ophthalmol 1971; 71 : 431-4.
6 Grove DL, Warren KS, Mahmoud AAF. Algorithms in the diagnosis and management of exotic disease. XV leprosy. J Infect Dis 1976; 134: 205-10.

7 Holmes WJ. The eyes of leprosy. Trans Ophthalmol Soc UK 1957; 81 : 397-420.

8 Hobbs HE, Harman DJ, Rees RJW, McDougall AC. Ocular histopathology in animals experimentally infected with Mycobacterium leprae and Molepramuriam. $\mathrm{Br} J$ Ophthalmol 1978; 62: 516-24.

9 Spyratos S. Ponction de la chambre antérieure sur un cas d'iritis lepreuse. Ann Oculistique 1954; 187: 538-45.

10 Voisin J, Lombard G. Uveite à hypopion chez un lepreux avec presence de bacilles de Hansen lors de l'examen de l'humeur. Bull Soc Ophtalmol Fr 1955; 32: $32-4$.

11 Sears ML. Ocular leprosy. Am J Ophthalmol 1958; 46: 359-61.

12 Michelson JB, Roth AM, Waring GO. Lepromatous iridocyclitis diagnosed by anterior chamber paracentesis. Am J Ophthalmol 1979; 88: 674-9.

13 Choyce DP. Kerato-uveal changes in leprosy and onchocerciasis. Proc $R$ Soc Med 1972; 65: 955-60.

14 Harley RD. Ocular leprosy in Panama. Am J Ophthalmol 1946; 29: 295-316.

15 Kirwan EWOG. Ocular leprosy. Proc R Soc Med 1955; 48: 112-8.

16 Drutz DJ, Chen TSN, Lu WH. Acid-fast bacilli demonstrated in the blood of leprosy patients. $N$ Engl J Med 1972; 287: 159-63.

17 Kennedy PJ. Ocular manifestations in leprosy. Am J Ophthalmol 1952; 35: 1360-4.

18 Holmes WJ. Leprosy of the eye. Lepr Rev 1957; 28 : 108-23.

19 Allen JH, Byers JL. The pathology of ocular leprosy. I. Cornea. Arch Ophthalmol 1960; 64: 216-20.

20 Choyce DP. The diagnosis and management of ocular leprosy. Br J Ophthalmol 1969; 53: 217-23.

21 Brand $M$. The care of the eye. The Star. Carville, Louisiana: 1980.

22 Soto MC, Palma S. Visual acuity in leprous patients. Arch Mem Soc Oftalmol Litoral 1948; 1 : 87-97.

23 Aparisi T. Ocular manifestations of leprosy. Arch Soc Oftalmol Hispano-Am 1950; 10: 107-21.

24 Wood DJ. Ocular leprosy. Br J Ophthalmol 1925; 9: $1-4$.

25 Carvalho JS. Ocular complications of leprosy. Rev Bras Oftalmol 1948; 6: 31-6.

26 Somerset EJ. Leprous lesions of the eye. $J$ All-India Ophthalmol Soc 1956; 4: 7-14.

27 Cameron AN. Leprosy and its ocular manifestations. Trans Ophthalmol Soc UK 1961; 81: 637-47.

28 Hobbs HE. The diagnosis of uveitis in leprosy. Lepr Rev $1963 ; 34: 226-30$.

29 Hobbs HE, Choyce DP. The blinding lesions of leprosy. Lepr Rev 1971; 42: 131-7.

30 Ticho V, Ben Sira. I. Ocular leprosy in Malawi. Br J Ophthalmol 1970; 53: 107-12.

31 King EF. The eye in leprosy. Br J Ophthalmol 1936; 20: 561-9.

32 Hansen GA, Bull OB. The Leprous Disease of the Eye. Christiana: 1873.

33 Barros $\mathrm{M}$ de. A clinical study of leprous iritis. Int $J$ Lepr 1940; 8: 353-60.

34 ffytche TJ. (1981) Cataract surgery in the management of the late complications of lepromatous leprosy in South Korea. Br J Ophthalmol 1981; 65: 243-8.

35 Pinkerton RJ. Leprosy of the eye. An analysis of the record of 512 cases of leprosy in the Hawaiian Islands. Arch Ophthalmol 1927; 56: 42-51.

36 Allen JH. The pathology of ocular leprosy. II. Miliary 
lepromas of iris. Am J Ophthalmol 1966; 61: 987-92.

37 Ebenezer R. Symposium on uveitis. Iritis in Leprosy. Proc All-India Ophthalmol Soc 1963; 19: 183-8.

38 Prendergast JJ. Ocular leprosy in the United States. Arch Ophthalmol 1940; 23: 112-37.

39 Beretti J, Cahuzac G. Lesions of ocular leprosy in New Caledonia. Arch Ophtalmol (Paris) 1970; 30: 313-20.

40 Prabhakaran K. Cataract in leprosy: a biochemical approach. Lepr Rev 1971 ; 42: 11-3.

41 Studdy P, Bird R, James DG, Sherlock S. Serum angiotensin-converting enzyme (SACE) in sarcoidosis and other granulomatous disorders. Lancet 1978; ii: 1331-4.

42 Schwartz B. Temperature gradients in rabbit eye. Invest Ophthalmol Visual Sci 1962; 1: 513-21.
43 Last RJ. Wolff's Anatomy of the Eye and Orbit. 6th ed. London: Lewis, 1968.

44 Minder R. Über die Sichtbarkeit der Leprosen Nervenkrankung in der Kornea an der Spaltlamp. Klin Monatsbl Augenheilkd 1929; 82: 36-40.

45 Richards WW, Arrington JW. Unsuspected ocular leprosy. Am J Ophthalmol 1969; 68: 492-9.

46 Harrell J. Ocular leprosy in the Canal Zone. Int J Lepr 1977 ; 45: 56-60.

47 Hashizuma H, Shionuma E. Electron microscopic studies of lepromatous changes in the iris. Int J Lepr 1965; 33: 61-82.

48 Swift TR, Bauschard FD. Pupillary reactions in lepromatous leprosy. Int J Lepr 1972; 40: 142-8. 